Научная статья

УДК 504.054:574.24(571.54)

DOI 10.18101/2587-7143-2021-2-50-60

\title{
ВЛИЯНИЕ АНТРОПОГЕННЫХ ФАКТОРОВ СРЕДЫ ОБИТАНИЯ НА ЗДОРОВЬЕ НАСЕЛЕНИЯ ГУСИНООЗЕРСКОГО ПРОМЫШЛЕННОГО УЗЛА
}

\section{(ㄱ) Ульзетуева Ирина Дабаевна}

кандидат географических наук, научный сотрудник лаборатории геоэкологии, Байкальский институт природопользования СО РАН

Россия, 670047, Улан-Удэ, ул. Сахьяновой, 6 idulz@mail.ru

\section{(C) Будаева Виктория Валерьевна} магистрант, Бурятский государственный университет имени Доржи Банзарова Россия, 670000, г.Улан-Удэ, ул. Смолина, 24а viktoriya.budaeva.94@mail.ru

\section{(C) Хахинов Вячеслав Викторович} доктор химических наук, профессор, заведующий кафедрой экологии и природопользования, Бурятский государственный университет имени Доржи Банзарова Россия, 670000, г. Улан-Удэ, ул. Смолина, 24а

khakhinov@mail.ru

\section{(C) Гомбоев Баир Октябрьевич}

доктор географических наук, главный научный сотрудник, Байкальский институт природопользования СО РАН Россия, 670047, Улан-Удэ, ул. Сахьяновой, 6 заведующий кафедрой географии и геоэкологии факультета биологии, географии и землепользования, профессор, Бурятский государственный университет имени Доржи Банзарова Россия, 670000, г. Улан-Удэ, ул. Смолина, 24а bgom@binm.ru

Аннотация. В статье приведена оценка влияния антропогенных факторов среды обитания на здоровье населения Гусиноозерского промышленного узла. Изучение влияния различных антропогенных факторов на качество водных ресурсов является весьма актуальным, поскольку питьевая вода как один из важнейших факторов определяет здоровье и качество жизни человека. Озеро Гусиное является основным источником хозяйственно-питьевого водоснабжения и одновременно приемником хозяйственно-бытовых и промышленных сточных вод. На экологическое состояние озера оказывают влияние Гусиноозерская ГРЭС, использующая озеро как охлаждающий водоем, из которого происходит водозабор и сброс термальных вод с ГРЭС, нерекультивированные терриконы вскрышных пород Холбольджинского угольного разреза. По результатам исследований рассмотрено токсическое действие высоких концентраций ряда тяжелых металлов на живые организмы. Рассчитана оценка неканцерогенного риска на здоровье мужчин и женщин при употреблении питьевых вод из оз. Гусиное. Установлено, что на территории Гусиноозерского промышленного узла 
И. Д. Ульзетуева, В. В. Будаева, В. В. Хахинов, Б. О. Гомбоев. Влияние антропогенных факторов среды обитания на здоровье населения Гусиноозерского промышленного узла

риск развития неканцерогенного эффекта на здоровье населения, связанного с качеством питьевой воды, является высоким.

Ключевые слова: антропогенные факторы, озеро Гусиное, оценка риска, питьевая вода

\section{Благодарности}

Работа выполнена в рамках государственного задания Байкальского института природопользования Сибирского отделения РАН.

\section{Для цитирования}

Влияние антропогенных факторов среды обитания на здоровье населения Гусиноозерского промышленного узла / И. Д. Ульзетуева, В. В. Будаева, В. В. Хахинов, Б. О. Гомбоев // Вестник Бурятского государственного университета. Биология, география. 2021. № 2. С. 50-60.

Проблема загрязнения водных ресурсов стала актуальной в последние несколько десятилетий, поскольку практически все источники воды, как поверхностные, так и подземные, подвергаются интенсивному антропогенному и техногенному воздействию. Влияние различных антропогенных факторов на качество водных ресурсов является предметом изучения во всем мире, поскольку питьевая вода как один из важнейших факторов определяет здоровье и качество жизни человека. По данным, приведенным в Стратегии экологической безопасности РФ на период до 2025 г., лишь 11\% сточных вод попадает в водные объекты РФ очищенными до установленных нормативов, это приводит к тому, что около 40\% населения страны регулярно использует воду, не соответствующую гигиеническим нормативам. Вследствие загрязнения питьевой воды химическими веществами и микроорганизмами увеличивается риск смертности и заболеваемости населения ${ }^{1}$.

Озеро Гусиное - самое крупное озеро на территории бассейна р. Селенги. Антропогенная нагрузка на водоем значительно увеличилась после пуска в эксплуатацию Гусиноозерской ГРЭС, в связи с чем резко возросло промышленное и хозяйственное использование вод оз. Гусиное. Озеро является не только основным источником хозяйственно-питьевого водоснабжения, но и приемником хозяйственно-бытовых и промышленных сточных вод, содержащих в своем составе тяжелые металлы. Кроме того, Гусиноозерская ГРЭС использует озеро как охлаждающий водоем, из которого происходит водозабор и сброс термальных вод с ГРЭС. На экологическое состояние озера оказывают влияние также нерекультивированные терриконы вскрышных пород Холбольджинского угольного разреза, расположенные вдоль всего восточного побережья. В настоящее время на берегу озера отходы с шахт угольного разреза Холбольджинский составляют более 260 млн кубометров шлака, с 2017 г. началась рекультивация терриконов [2].

На территории Гусиноозерского промышленного узла находится месторождение пресных подземных вод в долине р. Ельник, перспективное для водоснабжения г. Гусиноозёрска, испытывающего острый дефицит качественной питьевой воды. Попытки решения проблемы питьевого водоснабжения здесь предпринимаются на протяжении нескольких десятилетий. Эксплуатационные запасы ме-

${ }^{1}$ Стратегия экологической безопасности Российской Федерации на период до 2025 г. Министерство природных ресурсов и экологии Российской Федерации. Москва, 2015. 
сторождения «Ельник» предварительно оценены в начале 1980-х гг., а в начале 1990-х гг. проведена разведка запасов, но до сих пор не завершена из-за отсутствия финансирования [1].

По данным государственного доклада «О состоянии санитарно-эпидемиологического благополучия населения в Российской Федерации в 2017 г.», неудовлетворительное качество воды системы хозяйственно-питьевого водоснабжения на территории Российской Федерации является вторым по значимости неблагоприятным фактором среды обитания ${ }^{1}$. Употребление некачественной воды характеризуется высоким уровнем общей заболеваемости населения, связанной с негативными факторами среды обитания. Следовательно, актуальным является изучение химического состава вод озера Гусиное как важного фактора внешней среды, оказывающего влияние на здоровье населения, проживающего на данной территории.

Целью настоящей работы являются гидрохимические исследования поверхностных вод оз. Гусиное и оценка неканцерогенного риска для здоровья населения, проживающего в районе Гусиноозерского промышленного узла.

\section{Объекты и методы исследования}

Объектом исследования является вода озера Гусиное. Отбор проб был выполнен по ГОСТ 31861-2012 «Вода. Общие требования к отбору проб»². Методика исследований заключалась в определении основных компонентов химического состава воды озера Гусиное и оценке их качества с учетом нормативных критериев предельно допустимых концентраций (ПДК) загрязняющих веществ для водоемов рыбохозяйственного назначения ${ }^{3}$ и источников техногенного загрязнения.

Оценка риска развития неканцерогенных эффектов у мужского и женского населения в результате хронического потребления поверхностных вод из оз. Гусиное осуществлялась на основе значений коэффициента опасности (HQ) по методике, разработанной Американским агентством по охране окружающей среды (US EPA $)^{4}$. Преимуществом использованной методики оценки неканцерогенных рисков US EPA является возможность расчета суммарных рисков при повышенных концентрациях нескольких потенциально опасных компонентов, характеризующихся сходным механизмом воздействия на организм человека.

\section{Результаты и их обсуждение}

Хозяйственно-питьевое водоснабжение Гусиноозерского промышленного узла осуществляется за счет поверхностных вод озера Гусиное. Изучение макрокомпонентного состава вод озера Гусиное в исследуемый период (июль 2018 г.) показало, что воды имеют преимущественно среднюю минерализацию (380-

\footnotetext{
${ }^{1}$ Государственный доклад «О состоянии санитарно-эпидемиологического благополучия населения в Российской Федерации в 2017 г.». Москва, 2018.

${ }^{2}$ ГОСТ 31861-2012 «Вода. Общие требования к отбору проб»

${ }^{3}$ Об утверждении нормативов качества воды водных объектов рыбохозяйственного значения, в том числе нормативов предельно допустимых концентраций вредных веществ в водах водных объектов рыбохозяйственного значения: приказ Министерства сельского хозяйства РФ от 13.12.2016 г. № 552.

${ }^{4}$ The Integrated Risk Information System (IRIS), prepared and maintained by the U.S. Environmental Protection Agency (U.S. EPA). Health and Environmental Assessment, ECAD, Cincinnati, OH, 1987-1996.
} 
И. Д. Ульзетуева, В. В. Будаева, В. В. Хахинов, Б. О. Гомбоев. Влияние антропогенных факторов среды обитания на здоровье населения Гусиноозерского промышленного узла

481 мг/дм³), по щелочной реакции среды воды являются слабощелочными, значения рН в пределах 7,8-8,8, содержание кислорода варьировало в пределах 8,711,55 мг/дм ${ }^{3}$. Преобладающими ионами в макрокомпонентном составе вод являются гидрокарбонат-ионы (198-214 мг/дм³), сульфат-ионы (52,9-61,6 мг/дм³), ионы натрия $(44,2-50,7$ мг/дм³ $)$ и кальция $\left(33,8-48,0\right.$ мг/дм ${ }^{3}$ ). Содержание биогенных веществ (соединений азота и фосфора) также является повышенным в местах выраженной антропогенной нагрузки, к которым относятся места сброса сточных вод ЖКХ г. Гусиноозерска в р. Загустай. По всей акватории озера наблюдается повышенное содержание фторид-ионов, в концентрациях выше ПДКр/х (1,42-2,2 мг/дм³).

Проведенный анализ показал, что воды озера по макрокомпонентному составу являются сульфатно-гидрокарбонатными кальциево-натриевого типа. Сравнение результатов гидрохимических исследований, проведенных до строительства Гусиноозерской ГРЭС и начала промышленной разработки Холбольджинского угольного разреза в 1965 г., показало, что за 50 лет произошел рост минерализации воды с соответствующим увеличением содержания ионов в макрокомпонентном составе, в особенности сульфат-ионов и щелочных металлов [1; 5] (табл. 1).

Таблица 1

Результаты химического анализа проб воды оз. Гусиное, мг/дм³

\begin{tabular}{|c|c|c|c|c|c|c|c|c|c|c|c|c|c|c|}
\hline № & $\begin{array}{c}\text { Вод- } \\
\text { ный } \\
\text { объект }\end{array}$ & $\begin{array}{c}\text { Годы } \\
\text { изуче- } \\
\text { ния }\end{array}$ & 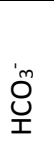 & $\stackrel{\dot{\tilde{N}}}{\stackrel{\tilde{U}}{ }}$ & 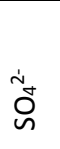 & $\frac{1}{U}$ & $\dot{\dot{u}}$ & $\begin{array}{l}\dot{m}_{+} \\
\dot{O}^{\prime}\end{array}$ & $\stackrel{\text { O }}{z}$ & $\stackrel{n}{2}$ & $\stackrel{+}{\widetilde{U}}$ & º & $\begin{array}{l}\frac{+}{4} \\
+ \\
+0 \\
Z\end{array}$ & $\sum_{\text {ионов }}$ \\
\hline 1 & \multirow{4}{*}{ 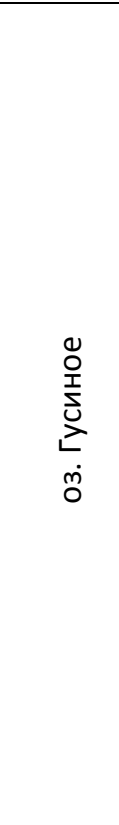 } & $\begin{array}{l}1965- \\
1967\end{array}$ & 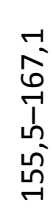 & & 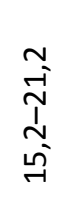 & 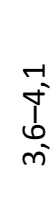 & 1 & $\begin{array}{l}n \\
\text { L } \\
0 \\
0 \\
1 \\
m \\
0 \\
0 \\
0 \\
0\end{array}$ & $\begin{array}{l}\text { nn } \\
\text { ñ } \\
0 \\
0 \\
1 \\
0 \\
0 \\
0\end{array}$ & 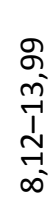 & 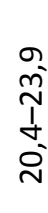 & \begin{tabular}{l}
$m$ \\
- \\
\multirow{1}{1}{} \\
$\infty$ \\
$N$
\end{tabular} & $\begin{array}{l}\text { İ } \\
\text { ñ } \\
n \\
\text { ñ }\end{array}$ & $\begin{array}{l}\hat{\sigma} \\
\stackrel{n}{N} \\
\hat{N} \\
\hat{N} \\
\stackrel{N}{N}\end{array}$ \\
\hline 2 & & 1974 & $\begin{array}{l}n \\
\infty \\
\stackrel{1}{1} \\
+ \\
\stackrel{1}{7}\end{array}$ & & 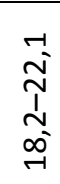 & $\begin{array}{l}\overrightarrow{1} \\
\infty \\
1 \\
b \\
-i\end{array}$ & & 1 & 1 & 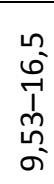 & $\begin{array}{l}\text { ì } \\
\text { ñ } \\
\text { in } \\
\text { ì }\end{array}$ & 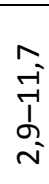 & $\begin{array}{l}+ \\
\text { Oे }\end{array}$ & $\begin{array}{l}\stackrel{\infty}{\infty} \\
\stackrel{N}{N} \\
\stackrel{\omega}{ન}\end{array}$ \\
\hline 3 & & $\begin{array}{l}1990- \\
1992\end{array}$ & $\begin{array}{l}\stackrel{m}{\vec{H}} \\
\underset{\infty}{\infty} \\
\stackrel{\sim}{\sim}\end{array}$ & & $\begin{array}{l}m \\
\stackrel{n}{1} \\
\infty \\
-1\end{array}$ & $\begin{array}{l}\underset{1}{1} \\
\infty\end{array}$ & & $\begin{array}{l}\infty \\
0 \\
0 \\
1 \\
1 \\
0 \\
0 \\
0\end{array}$ & $\begin{array}{l}0 \\
0 \\
1 \\
-1 \\
0\end{array}$ & 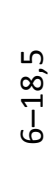 & $\underset{N}{\tilde{D}}$ & 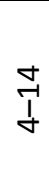 & 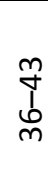 & $\begin{array}{l}\stackrel{\infty}{m} \\
\stackrel{m}{1} \\
\stackrel{N}{N}\end{array}$ \\
\hline 4 & & 2010 & $\begin{array}{l}m \\
\infty \\
\rightarrow \\
\text { ñ } \\
\end{array}$ & 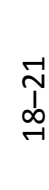 & $\begin{array}{l}\stackrel{+}{\mathfrak{n}} \\
\stackrel{m}{\sim}\end{array}$ & $\begin{array}{l}\text { సे } \\
\text { ñ } \\
\text { o }\end{array}$ & \begin{tabular}{l}
0 \\
\multirow{1}{1}{} \\
t \\
$-i$
\end{tabular} & $\begin{array}{l}-1 \\
0 \\
0 \\
1 \\
0 \\
0 \\
0 \\
0\end{array}$ & $\begin{array}{l}\text { ñ } \\
\text { o } \\
0\end{array}$ & 离 & 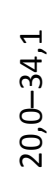 & $\begin{array}{l}\infty \\
\text { ñ } \\
1 \\
-1 \\
\text { á }\end{array}$ & $\frac{\vec{j}}{\frac{1}{n}}$ & 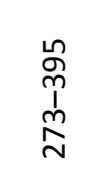 \\
\hline
\end{tabular}


ВЕСТНИК БУРЯТСКОГО ГОСУДАРСТВЕННОГО УНИВЕРСИТЕТА.

\begin{tabular}{|c|c|c|c|c|c|c|c|c|c|c|c|c|c|}
\hline 5 & $\begin{array}{l}2018 \\
\text { (лето)* }\end{array}$ & $\begin{array}{l}\stackrel{+}{\sim} \\
\stackrel{1}{1} \\
\stackrel{\infty}{\sim}\end{array}$ & 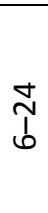 & $\begin{array}{l}0 \\
\text {-i் } \\
1 \\
\text { ô } \\
\text { กู }\end{array}$ & $\begin{array}{l}\hat{N} \\
\text { ñ } \\
\text { ñ }\end{array}$ & 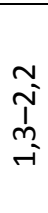 & 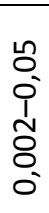 & $\begin{array}{l}-1 \\
\text { no } \\
0 \\
1 \\
1 \\
0 \\
0 \\
0 \\
0\end{array}$ & 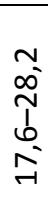 & 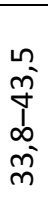 & 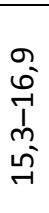 & 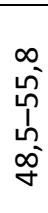 & $\begin{array}{l}{ }_{1}^{\infty} \\
\text { I } \\
\infty \\
\infty \\
m\end{array}$ \\
\hline
\end{tabular}

Примечание: * - представлены результаты, полученные авторами в рамках «Байкальской экспедиции»

Из установленного числа микроэлементов, присутствующих в поверхностных водах оз. Гусиное, 12 химических веществ представляют собой типичные компоненты загрязнения, опасные для здоровья. Увеличение содержания остальных металлов также приводит к снижению продуктивности водных экосистем и к потенциальной опасности для человека. Также рассмотрен ряд возможных факторов и условий, определяющих превышение значения ПДКр/х для каждого металла (табл. 2).

Таблица 2

Микроэлементный состав поверхностных вод озера Гусиное, потенциально опасный для здоровья

\begin{tabular}{|c|c|c|c|c|c|c|}
\hline \multirow[t]{2}{*}{ №ㄱ/п } & \multirow[t]{2}{*}{ CAS } & \multirow[t]{2}{*}{ Элемент } & \multirow{2}{*}{$\begin{array}{c}\text { ПДК*, } \\
(\text { мг/дм })\end{array}$} & \multicolumn{3}{|c|}{ Содержание (мг/дм3) } \\
\hline & & & & $\mathrm{C}_{\text {мин }}$ & $\mathrm{C}_{\text {макс }}$ & $\mathrm{C}_{\mathrm{cp}}$ \\
\hline \multicolumn{7}{|c|}{ Загрязнители питьевой воды, принятые ВОЗ в качестве приоритетных ${ }^{1}$} \\
\hline 1 & $7440-38-2$ & мышьяк (As)* & 0,010 & 0,0001 & 0,0005 & 0,0002 \\
\hline \multicolumn{7}{|c|}{ 2-й класс - высокоопасные } \\
\hline 2 & 7440-43-9 & кадмий (Cd)* & 0,001 & 0,0001 & 0,002 & 0,001 \\
\hline 3 & $7440-48-4$ & кобальт (Со)* & 0,100 & 0,001 & 0,005 & 0,004 \\
\hline 4 & $7440-02-0$ & никель (Ni)* & 0,020 & 0,001 & 0,003 & 0,002 \\
\hline 5 & 7439-92-1 & свинец (Pb)* & 0,010 & 0,001 & 0,007 & 0,005 \\
\hline 6 & 7439-98-7 & молибден (Мо) & 0,250 & 0,002 & 0,017 & 0,016 \\
\hline 7 & $7440-24-6$ & стронций (Sr) & 7,000 & 0,860 & 0,950 & 0,900 \\
\hline \multicolumn{7}{|c|}{ 3-й класс - умеренно опасные } \\
\hline 8 & $7440-58-8$ & медь (Cu) & 0,001 & 0,001 & 0,004 & 0,003 \\
\hline 9 & $7440-47-3$ & хром $(\mathrm{Cr})^{*}$ & 0,050 & 0,001 & 0,028 & 0,010 \\
\hline 10 & $7440-66-6$ & цинк (Zn) & 1,000 & 0,003 & 0,570 & 0,087 \\
\hline \multicolumn{7}{|c|}{ 4-й класс - органолептического действия } \\
\hline 11 & 7439-89-6 & железо (Fe) & 0,300 & 0,03 & 0,045 & 0,04 \\
\hline 12 & $7439-96-5$ & марганец (Mn) & 0,100 & 0,001 & 0,008 & 0,004 \\
\hline
\end{tabular}

Примечание: ${ }^{*}$ - канцерогены ${ }^{2}, * *-$ класс опасности установлен в соответствии с (ГН 2.1.5.689-98, 2003) $)^{3}$.

\footnotetext{
${ }^{1}$ URL: https://www.atsdr.cdc.gov/spl/index.html (дата обращения: 25.02.2021).

2 Руководство по оценке риска для здоровья населения при воздействии химических веществ, загрязняющих окружающую среду Р 2.1.10.1920-04. 2004 г.

${ }^{3}$ ГН 2.1.5.689-98 (Предельно допустимые концентрации (ПДК) химических веществ в воде водных объектов хозяйственно-питьевого и культурно-бытового водопользования:
} 
И. Д. Ульзетуева, В. В. Будаева, В. В. Хахинов, Б. О. Гомбоев. Влияние антропогенных факторов среды обитания на здоровье населения Гусиноозерского промышленного узла

Для расчета средних концентраций микроэлементов, представленных в таблице 2, были использованы также данные результатов, полученные в рамках «Байкальской экспедиции». В соответствии с ГН 2.1.5.689-98 «Предельно допустимые концентрации (ПДК) химических веществ в воде водных объектов хозяйственно-питьевого и культурно-бытового водопользования: гигиенические нормативы» ${ }^{1}$ для данных веществ были установлены классы опасности и сравнение их с ПДК. Сравнительный анализ ПДК химических веществ в воде водных объектов хозяйственно-питьевого и культурно-бытового водопользования и содержания микроэлементов показал, что для большинства обнаруженных химических веществ превышения гигиенических нормативов не наблюдается, за исключением меди и в случаях максимальных концентраций кадмия. На основании полученных результатов были рассчитаны дозы ежедневного поступления микроэлементов путем потребления питьевой воды из оз. Гусиное в организм мужчин и женщин.

В таблице 3 показаны результаты расчета дозы ежедневного поступления микроэлементов в организм мужчин и женщин.

Таблица 3

Доза хронического ежедневного поступления микроэлементов в организм человека и референтная (безопасная) доза, мг/кг*суст.

\begin{tabular}{|c|c|c|c|c|c|c|c|c|}
\hline & \multirow{3}{*}{ Элемент } & \multicolumn{6}{|c|}{ CDI } & \multirow{3}{*}{ RfD } \\
\hline & & \multicolumn{3}{|c|}{ Мужчины } & \multicolumn{3}{|c|}{ Женщины } & \\
\hline & & мин. & макс. & cp. & мин. & макс. & cp. & \\
\hline 1 & $\begin{array}{l}\text { Мышьяк } \\
(\mathrm{As})^{*}\end{array}$ & 0,000087 & 0,000608 & 0,000435 & 0,000100 & 0,000703 & 0,000502 & 0,0003 \\
\hline 2 & $\begin{array}{l}\text { Кадмий } \\
(\mathrm{Cd})^{*}\end{array}$ & 0,000087 & 0,000435 & 0,000174 & 0,000100 & 0,000502 & 0,000201 & 0,0005 \\
\hline 3 & $\begin{array}{l}\text { Кобальт } \\
(\text { Со)* }\end{array}$ & 0,000869 & 0,004345 & 0,003476 & 0,001004 & 0,00502 & 0,004016 & 0,020 \\
\hline 4 & $\begin{array}{l}\text { Никель } \\
(\mathrm{Ni})^{*}\end{array}$ & 0,000869 & 0,002607 & 0,001738 & 0,001004 & 0,003012 & 0,002008 & 0,020 \\
\hline 5 & $\begin{array}{l}\text { Свинец } \\
(\mathrm{Pb})^{*}\end{array}$ & 0,000869 & 0,006084 & 0,004345 & 0,001004 & 0,007029 & 0,00502 & 0,0035 \\
\hline 6 & $\begin{array}{l}\text { Молибден } \\
\text { (Мо) }\end{array}$ & 0,001738 & 0,014775 & 0,013906 & 0,002008 & 0,017069 & 0,016065 & 0,005 \\
\hline 7 & $\begin{array}{l}\text { Стронций } \\
\text { (Sr) }\end{array}$ & 0,747424 & 0,825643 & 0,782188 & 0,863516 & 0,953884 & 0,903679 & 0,600 \\
\hline 8 & $\begin{array}{l}\text { Медь } \\
\text { (Сu) }\end{array}$ & 0,000869 & 0,003476 & 0,002607 & 0,001004 & 0,004016 & 0,003012 & 0,019 \\
\hline
\end{tabular}

гигиенические нормативы. Москва: Российский регистр потенциально опасных химических и биологических веществ Минздрава России, 2003. 284 с.).

${ }^{1}$ ГН 2.1.5.689-98 (Предельно допустимые концентрации (ПДК) химических веществ в воде водных объектов хозяйственно-питьевого и культурно-бытового водопользования: Гигиенические нормативы. Москва: Российский регистр потенциально опасных химических и биологических веществ Минздрава России, 2003. 284 с. 
ВЕСТНИК БУРЯТСКОГО ГОСУДАРСТВЕННОГО УНИВЕРСИТЕТА. БИОЛОГИЯ, ГЕОГРАФИЯ

\begin{tabular}{|c|l|l|l|l|l|l|l|l|}
\hline 9 & $\begin{array}{l}\text { Хром } \\
(\mathrm{Cr})^{*}\end{array}$ & 0,000869 & 0,024335 & 0,008691 & 0,001004 & 0,028114 & 0,010041 & 0,005 \\
\hline 10 & $\begin{array}{l}\text { Цинк } \\
\text { (Zn) }\end{array}$ & 0,002607 & 0,495386 & 0,075611 & 0,003012 & 0,57233 & 0,087356 & 0,300 \\
\hline 11 & $\begin{array}{l}\text { Железо } \\
\text { (Fе) }\end{array}$ & 0,026073 & 0,039109 & 0,034764 & 0,030123 & 0,045184 & 0,040164 & 0,300 \\
\hline 12 & $\begin{array}{l}\text { Марганец } \\
\text { (Мn) }\end{array}$ & 0,000869 & 0,006953 & 0,003476 & 0,001004 & 0,008033 & 0,004016 & 0,100 \\
\hline
\end{tabular}

Как показывают расчеты, ежедневная доза поступления микроэлементов, являющихся потенциально опасными, в организм женщин является большей, чем у мужчин. Так, например, среднее суточное поступление кобальта, меди, железа в организм женщины сопоставима с максимальным его поступлением в организм мужчины. Кроме того, средние ежедневные дозы мышьяка, свинца, хрома, молибдена и стронция, поступающие в организмы как мужчин, так и женщин, превышают референтные (безопасные) дозы поступления в сутки, что может свидетельствовать о более выраженном их токсическом действии.

Оценка рисков токсического (неканцерогенного) действия химических элементов на здоровье мужского и женского населения проводилась на основании расчета индивидуальных коэффициентов опасности (HQi) и индекса опасности (HI), результаты расчетов приведены в таблице 4.

Таблица 4

Значения коэффициента (HQ) и индекса опасности (HI) у мужчин и женщин при потреблении поверхностных вод оз. Гусиное

\begin{tabular}{|c|c|c|c|c|c|c|c|}
\hline & \multirow[t]{3}{*}{ Элемент } & \multicolumn{6}{|c|}{$\mathrm{HQ}$} \\
\hline & & \multicolumn{3}{|c|}{ Мужчины } & \multicolumn{3}{|c|}{ Женщины } \\
\hline & & мин. & макс. & $\mathrm{cp}$. & мин. & макс. & $\mathrm{cp}$. \\
\hline 1 & Мышьяк (As)* & 0,2897 & 2,0279 & 1,4485 & 0,3347 & 2,3429 & 1,6735 \\
\hline 2 & Кадмий (Cd)* & 0,1738 & 0,8691 & 0,3476 & 0,2008 & 1,0041 & 0,4016 \\
\hline 3 & Кобальт (Со)* & 0,0435 & 0,2173 & 0,1738 & 0,0502 & 0,2510 & 0,2008 \\
\hline 4 & Никель (Ni)* & 0,0435 & 0,1304 & 0,0869 & 0,0502 & 0,1506 & 0,1004 \\
\hline 5 & Свинец (Pb)* & 0,2483 & 1,7382 & 1,2416 & 0,2869 & 2,0082 & 1,4344 \\
\hline 6 & Молибден (Мо) & 0,3476 & 2,9549 & 2,7811 & 0,4016 & 3,4139 & 3,2131 \\
\hline 7 & Стронций (Sr) & 1,2457 & 1,3761 & 1,3036 & 1,4392 & 1,5898 & 1,5061 \\
\hline 8 & Медь (Cu) & 0,0457 & 0,1830 & 0,1372 & 0,0528 & 0,2114 & 0,1585 \\
\hline 9 & Хром $(\mathrm{Cr})^{*}$ & 0,1738 & 4,8669 & 1,7382 & 0,2008 & 5,6229 & 2,0082 \\
\hline 10 & Цинк (Zn) & 0,0087 & 1,6513 & 0,2520 & 0,0100 & 1,9078 & 0,2912 \\
\hline 11 & Железо (Fe) & 0,0869 & 0,1304 & 0,1159 & 0,1004 & 0,1506 & 0,1339 \\
\hline 12 & Марганец (Mn) & 0,0087 & 0,0695 & 0,0348 & 0,0100 & 0,0803 & 0,0402 \\
\hline 13 & $\mathrm{HI}$ & 2,7159 & 16,215 & 9,6612 & 3,1376 & 18,7335 & 11,1619 \\
\hline
\end{tabular}

По результатам проведенных расчетов установлено, что наименьшую токсическую опасность (HQ) представляет марганец и никель, для которого коэффициент опасности менее 0,11 . Значимые коэффициенты опасности характерны для 
И. Д. Ульзетуева, В. В. Будаева, В. В. Хахинов, Б. О. Гомбоев. Влияние антропогенных факторов среды обитания на здоровье населения Гусиноозерского промышленного узла

кадмия, кобальта, меди, цинка и железа при сохранении их средних концентраций в воде, однако совместное их присутствие в воде увеличивает суммарную токсическую опасность. В случае присутствия в воде максимальных концентраций цинка неканцерогенный риск увеличивается у мужчин и женщин, а увеличение концентрации кадмия до его максимальных значений увеличивает канцерогенный риск у женщин. По мнению ВО3, железо и марганец, содержащиеся в питьевой воде в высоких концентрациях, не оказывают вред здоровью. В то же время эти элементы следует рассматривать в качестве приоритетных загрязнителей питьевых вод, носящих характер опосредованного риска для здоровья.

Высокая степень неканцерогенного риска характерна для 5 элементов: мышьяк, свинец, хром, молибден, стронций, коэффициенты опасности у которых выше 1 (HQ>1), где наибольший токсический риск обусловлен содержанием в воде молибдена и хрома.

Рассчитанный суммарный индекс опасности (HI) находится в пределах 2,71616,215 для мужчин и 3,138-18,733 для женщин, что свидетельствует о высокой вероятности развития токсических эффектов от действия мышьяка, свинца, хрома, молибдена и стронция, а также цинка и кадмия при сохранении их максимальных концентраций в потребляемой воде.

Следует отметить, что мышьяк, свинец и хром обладают доказанным канцерогенным действием, и в последующем постоянное потребление питьевой воды из озера Гусиное может вызвать не только хронические болезни, но развитие канцерогенного риска (онкологических заболеваний). Употребление воды, загрязненной мышьяком, является причиной возникновения заболеваний легких, включая нарушение функции дыхания, онкологические поражения легких, бронхоэктатическую болезнь. Действие мышьяка через питьевую воду на организм детей в раннем возрасте или в утробе матери может привести к возникновению легочной патологии, и это ведет к значительному увеличению смертности среди лиц молодого возраста от рака и бронхоэктатической болезни [3].

С учетом того, что избыток микроэлементов в потребляемой питьевой воде оказывает вредное влияние на здоровье человека, следовательно, наибольшую токсическую нагрузку в организме испытывают $[3 ; 4 ; 6]$ :

- центральная нервная система,

- пищеварительная система (желудок, печень),

- иммунная система,

- сердечно-сосудистая система,

- эндокринная система,

- система крови и кроветворных органов,

- мочеполовая система (почки),

- костная система,

- дыхательная система (легкие);

- кожа, слизистые оболочки (аллергические реакции).

Таким образом, качество питьевой воды зависит от условий водоснабжения населения в пределах Гусиноозерского промышленного узла, что является основой формирования показателей индивидуального здоровья жителей. Все это требует оптимизации условий водоснабжения населения крупного города и обеспечения их доброкачественной, физиологически полноценной питьевой водой. 


\section{Выводы}

Проведенные исследования в 2018 г. показали, что воды озера Гусиное по составу являются сульфатно-гидрокарбонатными кальциево-натриевого типа. Сравнение результатов гидрохимических исследований, проведенных до строительства Гусиноозерской ГРЭС и начала промышленной разработки Холбольджинского угольного разреза в 1965 г., показало, что за 50 лет произошел рост минерализации воды с соответствующим увеличением содержания ионов в макрокомпонентном составе, в особенности сульфат-ионов и щелочных металлов.

Результаты исследования микроэлементного состава вод в бассейне оз. Гусиное показали, что основными загрязняющими веществами являются медь, цинк, марганец, железо и стронций, содержание которых превышает значения ПДКр/х в несколько раз.

Количественная оценка риска с использованием коэффициента опасности позволила выделить в пределах района исследований потенциальные риски для населения при потреблении питьевой воды. Ежедневная доза поступления микроэлементов (кобальта, меди, железа) с потребляемой водой в организм женщин сопоставима с максимальным их поступлением в организм мужчины. Средние ежедневные дозы мышьяка, свинца, хрома, молибдена и стронция, поступающие в организмы мужчин и женщин, превышают референтные (безопасные) дозы поступления в сутки, что может свидетельствовать о более выраженном их токсическом действии.

Таким образом, в результате проведенных исследований установлено, что на территории Гусиноозерского промышленного узла риск развития неканцерогенного эффекта на здоровье населения, связанного с качеством питьевой воды, является высоким. Следовательно, требуется проведение определенных мероприятий для снижения риска здоровью, в том числе необходим поиск альтернативного и более безопасного источника водоснабжения. При этом следует учесть методологию оценки риска влияния качества питьевой воды на здоровье населения в системе эколого-гигиенического мониторинга, с помощью которой можно также проверить результативность и эффективность реализации планировочных и организационно-технических мероприятий в отношении снижения риска для здоровья населения.

\section{Литература}

1. Борисенко И. М., Пронин Н. М., Шайбонов Б. Б. Экология озера Гусиное. УланУдэ: Изд-во БНЦ СО РАН, 1994. 199 с. Текст: непосредственный.

2. Гуржапов Б. О., Цыдыпов Б. З., Гармаев Е. Ж. Оценка распространения теплового загрязнения оз. Гусиное от сбросов Гусиноозерской ГРЭС // Проблемы устойчивого развития региона: материалы VIII Школы-семинара молодых ученых России. Улан-Удэ: Изд-во БНЦ СО РАН, 2016. С. 80-84. Текст: непосредственный.

3. Насолодин В. В., Широков В. Л., Люсин А. В. Взаимодействие микроэлементов в процессе их обмена в организме // Вопросы питания. 1999. № 4. С. 10-13. Текст: непосредственный.

4. Черных Н. А., Баева Ю. И. Тяжёлые металлы и здоровье человека // Вестник РУДН. 2004. № 1. С. 125-134. Текст: непосредственный.

5. Hydro-chemical characteristics of the Selenga river / V. V. Khakhinov, L. N. Korsun, I. D. Ul'zetueva, L. Janchivdorg // Survey of Mongolian aquatic ecosystems in a changing climate: Results, new approaches and future outlook. Ulaanbaatar. 2010. P. 46. 
И. Д. Ульзетуева, В. В. Будаева, В. В. Хахинов, Б. О. Гомбоев. Влияние антропогенных факторов среды обитания на здоровье населения Гусиноозерского промышленного узла

6. Vasak M., Kagi J. H. R // Metal Ions Biol. Syst. 1983. Vol. 15. P. 213.

Статья поступила в редакиию 17.03.2021; одобрена после рецензирования 08.04.2021; принята к публикации 26.04.2021.

\section{INFLUENCE OF ANTHROPOGENIC ENVIRONMENTAL FACTORS \\ ON THE HEALTH OF POPULATION \\ OF GUSINOOZYORSK INDUSTRIAL HUB}

Irina D. Ulzetueva

Cand. Sci. (Geogr.), Researcher of Geoecology Laboratory,

Baikal Institute of Nature Management SB RAS

6 Sakhyanovoy St., Ulan-Ude 670047, Russia

idulz@mail.ru

Viktoria V. Budaeva

Master's Student,

Dorzhi Banzarov Buryat State University

24a Smolina St., Ulan-Ude 670000, Russia

viktoriya.budaeva.94@mail.ru

Vyacheslav V. Khakhinov

Dr. Sci. (Chemistry), Prof.,

Head of Ecology and Nature Management Department,

Dorzhi Banzarov Buryat State University

24a Smolina St., Ulan-Ude 670000, Russia

khakhinov@mail.ru

Bair O. Gomboev

Dr. Sci. (Geogr.), Chief Researcher,

Baikal Institute of Nature Management SB RAS

6 Sakhyanovoy St., Ulan-Ude 670047, Russia

Prof., Head of Geography and Geoecology Department,

Faculty of Biology, Geography and Land Use,

Dorzhi Banzarov Buryat State University

24a Smolina St., Ulan-Ude 670000, Russia

bgom@binm.ru

Abstract. The article assesses the impact of anthropogenic environmental factors on the health of population of Gusinoozyorsk industrial hub. The study of the influence of various anthropogenic factors on the quality of water is highly relevant, since drinking water is one of the most important factors that determines the health and quality of human life. Lake Gusinoye is the main source for utility and drinking water supply, and at the same time a receiver of domestic and industrial wastewater. The ecological state of the lake is exposed to the impact of Gusinoozyorsk power station, which uses it as a cooling reservoir, and unremediated spoil tips of overburden rocks of Kholboldzhinsky coal mine. Based on the research results we analyzed the toxic effect of high concentrations of a number of heavy metals on living organisms. We evaluated non-carcinogenic risk to the health of men and women when drinking water from the lake Gusinoye, and came to the conclusion that on the ter- 
ritory of Gusinoozyorsk industrial hub the risk of developing a non-carcinogenic effect on the health of population associated with the quality of drinking water is high.

Keywords: anthropogenic factors, Lake Gusinoye, risk assessment, drinking water

\section{For citation}

Ulzetueva I. D., Budaeva V. V., Khakhinov V. V., Gomboev B. O. Influence of Anthropogenic Environmental Factors on the Health of Population of Gusinoozyorsk Industrial Hub. Bulletin of Buryat State University. Biology. Geography. 2021; 2: 50-60 (In Russ.).

The article was submitted 17.03.2021; approved after reviewing 08.04.2021; accepted for publication 26.04.2021. 